\title{
Effect of cooking brassica vegetables on the subsequent hydrolysis and metabolic fate of glucosinolates
}

\author{
Vanessa Rungapamestry ${ }^{1 *}$, Alan J. Duncan ${ }^{2}$, Zoë Fuller ${ }^{2}$ and Brian Ratcliffe ${ }^{1}$ \\ ${ }^{1}$ School of Life Sciences, The Robert Gordon University, St Andrew Street, Aberdeen AB25 1HG, UK \\ ${ }^{2}$ The Macaulay Institute, Craigiebuckler, Aberdeen AB15 8QH, UK
}

\begin{abstract}
The protective effects of brassica vegetables against cancer may be partly related to their glucosinolate content. Glucosinolates are hydrolysed by plant myrosinase following damage of plant tissue. Isothiocyanates are one of the main groups of metabolites of glucosinolates and are implicated in the preventive effect against cancer. During cooking of brassica the glucosinolate-myrosinase system may be modified as a result of inactivation of plant myrosinase, loss of enzymic cofactors such as epithiospecifier protein, thermal breakdown and/or leaching of glucosinolates and their metabolites or volatilization of metabolites. Cooking brassica affects the site of release of breakdown products of glucosinolates, which is the upper gastrointestinal tract following consumption of raw brassica containing active plant myrosinase. After consumption of cooked brassica devoid of plant myrosinase glucosinolates are hydrolysed in the colon under the action of the resident microflora. Feeding trials with human subjects have shown that hydrolysis of glucosinolates and absorption of isothiocyanates are greater following ingestion of raw brassica with active plant myrosinase than after consumption of the cooked plant with denatured myrosinase. The digestive fate of glucosinolates may be further influenced by the extent of cell rupture during ingestion, gastrointestinal transit time, meal composition, individual genotype and differences in colonic microflora. These sources of variation may partly explain the weak epidemiological evidence relating consumption of brassica to prevention against cancer. An understanding of the biochemical changes occurring during cooking and ingestion of brassica may help in the design of more robust epidemiological studies to better evaluate the protective effects of brassica against cancer.
\end{abstract}

Brassica: Glucosinolate hydrolysis: Isothiocyanates: Storage, preparation and cooking

Epidemiological studies suggest that the protective effects of brassica vegetables against cancers of the gastrointestinal tract and lungs may be partly related to their content of glucosinolates (van Poppel et al. 1999). Glucosinolates are $\beta$-thioglucoside $N$-hydrosulfates present in brassica vegetables such as broccoli (Brassica oleracea var. italica), cauliflower (Brassica oleracea var. botrytis), cabbage (Brassica oleracea var. capitata), Brussels sprouts (Brassica oleracea var. gemmifera) and turnip (Brassica campestris ssp. rapifera), and in condiments such as mustard (Sinapis alba; Fahey et al. 2001). Many comprehensive reviews have addressed the occurrence and biochemistry of glucosinolates in brassica (Fenwick et al. 1983; Fahey et al. 2001; Mithen, 2001). Glucosinolates co-exist with, but are physically separated from, a plant thioglucosidase, myrosinase, within a 'glucosinolate-myrosinase system' (Bones \&
Rossiter, 1996). During handling, processing or ingestion of brassica rupture of cellular membranes allows contact between glucosinolates and myrosinase. The myrosinasemediated hydrolysis of glucosinolates generates an unstable aglycone intermediate, thiohydroxamate- $O$-sulfonate, which is immediately converted to a wide range of bioactive metabolites, including isothiocyanates, thiocyanates, nitriles and cyanoepithioalkanes (Fenwick et al. 1983; Bones \& Rossiter, 1996). The volatile metabolites are associated with the typical bitter and hot flavour of brassica (Fenwick et al. 1983). One of the principal proposed mechanisms of chemo-protection involves isothiocyanates, which may influence the process of carcinogenesis through various molecular signalling mechanisms (induction of xenobioticmetabolizing enzymes and apoptosis, arrest of cell cycle progression and other mechanisms that are still being 
elucidated) and this aspect has been extensively reviewed elsewhere (Keum et al. 2004; Zhang et al. 2006). However, nitriles and other minor metabolites have been shown to be toxic in laboratory rodents (Fenwick \& Heaney, 1983).

The extent of hydrolysis of glucosinolates by plant myrosinase and the structure and concentration of the metabolites formed may be influenced by various features of the hydrolysis environment. Intrinsic factors such as coexisting plant myrosinase and its cofactors ascorbic acid, epithiospecifier protein (ESP) or $\mathrm{Fe}^{2+}$ and extrinsic factors such as $\mathrm{pH}$ and temperature have been shown to affect the hydrolysis of glucosinolates in vitro (Fenwick et al. 1983; Ludikhuyze et al. 2000). For example, isothiocyanates are produced at a neutral $\mathrm{pH}$, while nitriles are formed in an acidic environment or in the presence of $\mathrm{Fe}^{2+}$ during the myrosinase-mediated hydrolysis of aliphatic glucosinolates (Bones \& Rossiter, 1996). When $\mathrm{Fe}^{2+}$ and ESP, a small heat-labile peptide cofactor to myrosinase (Tookey, 1973), are present cyanoepithioalkanes are the major metabolites produced from alkenyl glucosinolates (progoitrin, sinigrin, gluconapin and glucobrassicanapin; Bones \& Rossiter, 1996). Lambrix et al. (2001) have reported that ESP can promote the formation of simple nitriles from hydrolysis of non-alkenyl aliphatic glucosinolates. Conditions of storage, preparation and cooking of brassica may therefore influence the hydrolysis of glucosinolates to their metabolites and, in turn, alter the physiological consequences of ingesting them.

Following ingestion of cooked brassica, a second phase of hydrolysis of glucosinolates may occur in the gastrointestinal tract under the action of the colonic microflora (Rabot et al. 1993; Michaelsen et al. 1994). The digestive and post-absorptive fate of glucosinolates in rodents and human subjects may be influenced by an array of factors such as the activity of plant myrosinase ingested, the extent of chewing, the nature of the meal containing brassica, the composition of the gut microflora and genotypic variation in post-absorptive metabolism (Shapiro et al. 2001; Rouzaud et al. 2003; Seow et al. 2005).

The glucosinolate-myrosinase system is subject to variation throughout the food chain (Dekker \& Verkerk, 2003), from agronomic conditions (Brown et al. 2002; Farnham et al. 2004) to storage, transport (Vallejo et al. 2003) and processing (Devos \& Blijleven, 1988). Major diversity of glucosinolate concentration (Kushad et al. 1999) and myrosinase activity (Wilkinson et al. 1984; Pocock et al. 1987) have been reported within and between brassica species. These sources of variability, coupled with differences between individuals in the metabolism of isothiocyanates (Seow et al. 2005), may partly explain the rather weak and inconsistent epidemiological evidence relating brassica consumption to preventive effects against cancer in man, especially in cohort studies (International Agency for Research on Cancer, 2004).

\section{Fate of the glucosinolate-myrosinase system during the storage, preparation and cooking of brassica}

Brassica vegetables generally undergo a variety of postharvest processes, including storage, preparation and cooking, before they are consumed. During these stages the glucosinolate-myrosinase system may be modified. Dekker et al. (2000) have estimated that the concentration of glucosinolates in brassica may vary by $5-10$-fold at each step of the food production chain because of differences attributed to cultivar, environmental and genetic factors, industrial processing, storage and domestic cooking. The cumulative nature of this variation at the various steps of the food production chain leads to considerable uncertainty in assessing rates of exposure of glucosinolates and their metabolites at target tissues.

Despite the extensive literature on the hydrolysis of glucosinolates, their distribution in fresh brassica and their health benefits, information on the effects of processing of brassica on the glucosinolate-myrosinase system is relatively scarce and inconsistent. The different sources of variability throughout the food production chain together with subtle differences between similar methods of food processing and different analytical techniques used in these experiments make direct comparison and interpretation of the data difficult.

\section{Effect of storage and preparation, before domestic cooking, on the concentration of glucosinolates in brassica vegetables}

Rangkadilok et al. (2002) have investigated the effect of post-harvest and packaging conditions on glucoraphanin concentrations in freshly-harvested broccoli heads. Cellular deterioration occurs more rapidly after storing broccoli at $20^{\circ} \mathrm{C}$ in open boxes than in perforated polymeric bags. Glucoraphanin concentration is reduced by $56 \%$ after storing broccoli for $3 \mathrm{~d}$ in an open environment or for $7 \mathrm{~d}$ in polymeric bags, as a result of hydrolysis of glucoraphanin by plant myrosinase to a greater extent in the open environment. Similarly, Rodrigues \& Rosa (1999) have reported a decline of 82 and $79 \%$ in glucoraphanin and total glucosinolate concentrations respectively when freshly-harvested broccoli inflorescences are stored at room temperature for $5 \mathrm{~d}$.

Refrigerated storage of brassica has produced more variable results. Glucoraphanin in broccoli heads stored at $4^{\circ} \mathrm{C}$ in open boxes or packaged in perforated polymeric bags is unaltered for $\leq 1$ week (Rangkadilok et al. 2002), while a reduction of 31 and $16 \%$ in glucoraphanin and total glucosinolate concentrations respectively has been observed after refrigerating broccoli for $5 \mathrm{~d}$ (Rodrigues \& Rosa, 1999). Following a simulation of refrigerated transport of freshly-harvested broccoli inflorescences, total glucosinolate concentration is reduced by $71 \%$, with a further decline of $31 \%$ after a simulated retail sale period. The loss in glucosinolates reported in the latter two studies, as compared with the unaltered concentrations observed by Rangkadilok et al. (2002), may be a result of inflorescences being more prone to hydrolysis of glucosinolates by plant myrosinase at the cut surfaces compared with whole broccoli heads.

Despite the general decline in total glucosinolates during storage of brassica, the rate of loss of individual glucosinolates has been shown to vary between and within plant varieties, and as a result of different storage conditions. 
Vallejo et al. (2003) have shown a lower reduction of aliphatic glucosinolates (reduced by 40\%) compared with indole glucosinolates (reduced by $78 \%$ ) after broccoli inflorescences, wrapped in polymeric film, are stored for a week at $1^{\circ} \mathrm{C}$. In contrast, refrigeration over $5 \mathrm{~d}$ is sufficient to maintain indole glucosinolate concentrations compared with a reduction after storing broccoli inflorescences at room temperature over the same time period (Rodrigues \& Rosa, 1999).

Brassica are often cut or chopped before they are cooked and such processes may lead to unpredictable changes in individual glucosinolate concentrations. For example, in one study (Verkerk et al. 2001) that used a range of vegetables the total indole glucosinolate concentration in white cabbage was found to increase 5-fold, with aliphatic glucosinolates remaining unchanged in vegetables that were chopped and left for $48 \mathrm{~h}$. In contrast, glucobrassicin was found to be increased $3 \cdot 5$-fold in red cabbage, with other glucosinolate concentrations being unchanged. Following storage of chopped broccoli, a decline was noted for the aliphatic glucosinolates, progoitrin and glucoraphanin. The authors attribute the unpredictable effects of tissue damage to two opposing mechanisms. The reduction in glucosinolates is attributed to plant myrosinase-mediated hydrolysis of glucosinolates at the cut surfaces, while a stress-induced synthesis of glucosinolates is held to be responsible for observed increases in glucosinolate concentrations. Being water-soluble glucosinolates can also be affected by washing conditions during the preparation of brassica vegetables. For example, washing brassica after cutting, use of hot water or longer durations of soaking brassica in water during washing can promote the loss of glucosinolates (Benner et al. 2003). These findings suggest that glucosinolate concentrations in brassica vegetables may be reduced even before they reach the consumer for domestic processing and consumption.

\section{Effect of cooking processes on the glucosinolate-myrosinase system}

When brassica vegetables are cooked, the glucosinolatemyrosinase system is altered as a result of partial or total inactivation of myrosinase, thermal or plant myrosinasemediated breakdown of glucosinolates, loss of enzymic cofactors, leaching of glucosinolates and their metabolites into the cooking medium or volatilization or thermal degradation of the metabolites (Dekker et al. 2000). These changes are mostly influenced by the duration and method of cooking, the type of vegetable matrix and the extent of its cellular disruption, and the chemical structure of the glucosinolate precursors.

Changes in total glucosinolate concentration. Oerlemans et al. (2006) have reported that thermal degradation of most glucosinolates in red cabbage devoid of plant myrosinase occurs at $>110^{\circ} \mathrm{C}$. Glucosinolates appear therefore to be relatively heat stable during relatively short durations of domestic cooking, where the internal temperature of the brassica is not usually $>100^{\circ} \mathrm{C}$.

The most-commonly-reported mechanism for the loss of glucosinolates in boiled brassica vegetables is through leaching into the cooking water after cell lysis. Loss of glucosinolates during boiling may be partly related to the size of cut pieces of brassica (Rosa \& Heaney, 1993), whether it is cooked in cold or boiling water, the amount of vegetable: water used (Dekker et al. 2000) and the duration of cooking (Ciska \& Kozlowska, 2001). Despite using similar conditions of boiling, Sones et al. (1984) have shown a loss in total glucosinolates of approximately $28 \%$ after cooking cabbage in boiling water for $10 \mathrm{~min}$, while Rosa \& Heaney (1993) have reported a loss $>50 \%$. The latter used shredded or coarsely-chopped cabbage, which provides a larger surface area for leaching of glucosinolates into the cooking water compared with whole leaves of cabbage used by Sones et al. (1984). Dekker et al. (2000) have shown that the extent of leaching of glucosinolates during boiling of broccoli is negatively related to the amount of broccoli : cooking water used. Broccoli added to cold water, compared with boiling water, before boiling leads to a higher loss of total glucosinolates that cannot be accounted for by leaching. These authors explain the unaccountable losses as the result of thermal or enzymic degradation or volatilization of glucosinolates during cooking.

Ciska \& Kozlowska (2001) have studied time-course changes in glucosinolate concentration of sliced cabbage during boiling for $30 \mathrm{~min}$. The greatest reduction (by 35\%) in total glucosinolate concentration occurs after boiling cabbage for $5 \mathrm{~min}$, followed by a decline of $5-10 \%$ in total glucosinolate concentration after each subsequent $5 \mathrm{~min}$ interval until after $25 \mathrm{~min}$ of cooking. Total glucosinolate concentration is reduced by $87 \%$ after $30 \mathrm{~min}$. Contrary to the findings discussed earlier, Ciska \& Kozlowska (2001) have shown that leaching only accounts for a decline of $10 \%$ in total glucosinolate concentration after boiling cabbage for $\leq 25 \mathrm{~min}$. After boiling cabbage for $30 \mathrm{~min}$ there is a $\leq 20 \%$ increase in leaching of total glucosinolates as a result of the release of cell-bound glucosinolates after a marked disruption of the cell walls during cooking (Ciska \& Kozlowska, 2001). While the rate of leaching of total glucosinolates is fairly steady throughout boiling, unaccountable losses of glucosinolates (presumably thermal degradation) increase from 23 to $75 \%$ after boiling cabbage for 5 and $30 \mathrm{~min}$ respectively (Ciska \& Kozlowska, 2001). It is likely, therefore, that the loss of glucosinolates via leaching is a function of the cut size of brassica and the amount of brassica:water used, while unaccountable losses of glucosinolates may be mostly influenced by the duration and extent of heating.

Other methods of cooking such as blanching or microwaving have generated even more variable results. Blanching vegetables before freezing reduces microbial load and inactivates enzymes responsible for textural changes during frozen storage (Brewer et al. 1995). Water blanching of whole Brussels sprouts (Wathelet et al. 1996) or broccoli (Goodrich et al. 1989) reduces total glucosinolate concentration by twice as much as steam blanching, which led to less leaching. Conversely, Goodrich et al. (1989) have reported that the loss of total glucosinolates is higher after steam blanching Brussels sprouts than after water blanching, using similar conditions to those used for broccoli, and they explain the opposing effect of the blanching treatments in terms of the physical form of the 
two vegetables. The tight compact structure of Brussels sprouts may be more resistant to leaching during water blanching and perhaps more susceptible to unaccountable losses during steam blanching than the loose structure of broccoli. Insufficient detail was provided on the cut size of brassica and on temporal effects during sampling preparation to arrive at more definite explanations for the conflicting findings.

Vallejo et al. (2002) have shown a reduction of $74 \%$ in total glucosinolate concentration after microwaving $150 \mathrm{~g}$ broccoli in $150 \mathrm{ml}$ water at $1000 \mathrm{~W}$ for $5 \mathrm{~min}$. They suggest that the decline may be a result of leaching of glucosinolates followed by high water evaporation containing the leached glucosinolates, although the extent of water evaporation was not determined. They also speculate that thermal degradation of glucosinolates occurs during microwaving, but mention that this outcome could not be confirmed as metabolites of glucosinolates were not analysed. However, thermal degradation of glucosinolates would not necessarily yield conventional metabolites. In contrast, Verkerk \& Dekker (2004) have reported an increase of $78 \%$ in total glucosinolate concentration after microwaving $300 \mathrm{~g}$ coarsely-chopped red cabbage under similar conditions ( $900 \mathrm{~W}$ for $4 \mathrm{~min} 48 \mathrm{~s}$ ), although this outcome is attributed to a higher chemical extractability of glucosinolates from cooked cabbage compared with its raw counterpart and may therefore have been an analytical artefact. When comparing their results with those of Vallejo et al. (2002) Verkerk \& Dekker (2004) suggest that broccoli may be more prone to cellular disruption and loss of glucosinolates than cabbage because of its loose structure.

Changes in individual glucosinolate concentrations. Indole glucosinolates appear more liable to leaching or unaccountable losses than aliphatic glucosinolates in a range of brassica (Goodrich et al. 1989; Ciska \& Kozlowska, 2001; Vallejo et al. 2002). The loss of total indole glucosinolates after boiling cabbage for $10-30 \mathrm{~min}$ is reported to be $5-10 \%$ higher than the corresponding decline in aliphatic glucosinolates. During this process the loss of indole glucosinolates as a result of leaching is five times higher than that of aliphatic glucosinolates (Ciska \& Kozlowska, 2001).

The behaviour of individual aliphatic or indole glucosinolates may vary between and within varieties of brassica, as well as between cooking methods. During boiling of cabbage glucoiberin has been found to be the most thermolabile of the aliphatic glucosinolates, while glucobrassicin and 4-methoxy glucobrassicin show the greatest reduction in concentration among the indole glucosinolates because of their high heat lability and leaching potential (Rosa \& Heaney, 1993; Ciska \& Kozlowska, 2001). Conversely, Vallejo et al. (2002) have shown that the stability of glucoiberin is similar to that of other aliphatic glucosinolates after subjecting broccoli to steaming, microwaving or boiling, while glucoraphanin is mostly retained after steaming or boiling broccoli, but is markedly reduced by $64.5 \%$ after microwaving. Glucobrassicin and neoglucobrassicin, the least stable of the glucosinolates, are reduced by $20 \%$ when broccoli is microwaved or boiled. After steaming broccoli, however, neoglucobrassicin remains unchanged, while glucobrassicin concentration is reduced by $60 \%$ (Vallejo et al. 2002). These findings indicate that individual glucosinolates may behave differently according to the cooking method. Water blanching of broccoli reduces glucoiberin, glucoraphanin and glucobrassicin concentrations to similar extents (loss of $80 \%$ in each case), while water blanching of Brussels sprouts produces variable losses in progoitrin $(2 \%)$, sinigrin $(4 \%)$ and glucobrassicin (13\%; Goodrich et al. 1989).

While aliphatic glucosinolates are generally more stable than indole glucosinolates during the cooking of brassica, the relative stability of individual glucosinolates may be a function of their respective chemical structure (Wathelet et al. 1996). Furthermore, the relative thermostability of individual glucosinolates has been shown to vary with heating temperature (Oerlemans et al. 2006). Heating freeze-dried cabbage, containing denatured plant myrosinase, at $80-123^{\circ} \mathrm{C}$ for $5-360 \mathrm{~min}$ in the absence of water excludes the confounding effects of leaching or hydrolysis of glucosinolates during cooking. Thermal degradation of glucosinolates is limited at $\leq 110^{\circ} \mathrm{C}$, with a rate of degradation of indole glucosinolates up to seventyfive times that of aliphatic glucosinolates. At $>110^{\circ} \mathrm{C}$ thermal degradation increases and the difference in thermostability between indole and aliphatic glucosinolates is reduced. At $120^{\circ} \mathrm{C}$ indole and aliphatic glucosinolates have similar rates of degradation, except for progoitrin and gluconapin, which were degraded at a rate five and eight times lower than other glucosinolates respectively (Oerlemans et al. 2006).

Changes in plant myrosinase activity. The activity of plant myrosinase and its isoenzymes can vary extensively between and within brassica species (Wilkinson et al. 1984; Pocock et al. 1987; Yen \& Wei, 1993) and in different parts of the plant (Pihakaski \& Pihakaski, 1978). The heat stability of myrosinase may be dependent on its source (Fenwick et al. 1983). When myrosinase extracted from broccoli and purified as a powder is heated, it is markedly inactivated at $\geq 40^{\circ} \mathrm{C}$ and loses approximately $90 \%$ of its activity after heating at $60^{\circ} \mathrm{C}$ for $3 \mathrm{~min}$ at pH 6.55 (Ludikhuyze et al. 1999). Conversely, $30 \mathrm{~min}$ of heating homogenized red or white cabbage at $\mathrm{pH} 7 \cdot 00$ and $70^{\circ} \mathrm{C}$ is required to reduce its myrosinase activity by $>90 \%$ (Yen \& Wei, 1993). An optimum temperature of $30^{\circ} \mathrm{C}$ has been reported for myrosinase from broccoli (Ludikhuyze et al. 2000), which is lower than optimum temperatures of $60^{\circ} \mathrm{C}$ observed for myrosinase from red and white cabbage (Yen \& Wei, 1993) and $50^{\circ} \mathrm{C}$ for myrosinase from Brussels sprouts (Springett \& Adams, 1989). The higher thermostability of plant myrosinase reported in cabbage (Yen \& Wei, 1993) and Brussels sprouts (Springett \& Adams, 1989), compared with broccoli (Ludikhuyze et al. 1999; Ludikhuyze et al. 2000), may be partly confounded by the effect of heat on disruption of plant cells. It can be argued that the study of the effect of heat on plant myrosinase within its vegetable tissue may be more physiologically relevant than when it is extracted and then subjected to thermal treatment.

Few studies have investigated the effect of cooking brassica vegetables on plant myrosinase activity as well as glucosinolate concentrations (Wathelet et al. 1996; 
Verkerk \& Dekker, 2004), although there has been speculation (Vallejo et al. 2002; Kassahun et al. 1995) that changes in glucosinolate concentrations during cooking of brassica vegetables may be a result of their plant myrosinase activity. Wathelet et al. (1996) have shown that plant myrosinase is completely inactivated after water blanching whole Brussels sprouts at $95^{\circ} \mathrm{C}$ for $10 \mathrm{~min}$ or steam blanching at $105^{\circ} \mathrm{C}$ for $5 \mathrm{~min}$; glucosinolate concentrations are reduced by 13 or $3 \%$ respectively by these treatments. While the reduction in glucosinolates is mostly a result of leaching after water blanching Brussels sprouts, the decrease in plant myrosinase activity is positively related to blanching temperature. Similarly, Verkerk \& Dekker (2004) have reported that on microwaving red cabbage at different energy inputs its plant myrosinase activity is associated with the temperature of the cooked cabbage for each energy input. Plant myrosinase is still active after microwaving $300 \mathrm{~g}$ chopped red cabbage at $180 \mathrm{~W}$ for $25 \mathrm{~min}$, with the temperature of cooked cabbage reaching $90^{\circ} \mathrm{C}$, but is completely destroyed after microwaving at $900 \mathrm{~W}$ for about $5 \mathrm{~min}$, at which point the temperature of cooked cabbage is $100^{\circ} \mathrm{C}$.

The heat stability of ascorbic acid is also of interest, since ascorbic acid is a cofactor of plant myrosinase (Shikita et al. 1999; Ludikhuyze et al. 2000). Ascorbic acid is known to be one of the water-soluble nutrients in the vegetable matrix most affected by heat, $\mathrm{pH}$ and light. Its concentration may vary markedly between cooking methods (Yadav \& Sehgal, 1995; Begum \& Brewer, 2001; Vallejo et al. 2002).

Effect of cooking brassica on the glucosinolatemyrosinase system. Information on the effect of the extent of cooking on the glucosinolate-related characteristics of brassica and on the relationship between the residual glucosinolate concentrations and plant myrosinase activity and the formation of metabolites of glucosinolates produced, is limited. In cabbage the glucosinolate sinigrin is hydrolysed by plant myrosinase to allyl isothiocyanate (AITC), allyl cyanide and, in the presence of ESP, 1-cyano-2,3-epithiopropane (Fig. 1). In a recent study (Rungapamestry et al. 2006) $120 \mathrm{~g}$ cabbage was microwaved at $750 \mathrm{~W}$ or steamed for six time periods over $7 \mathrm{~min}$. The total glucosinolate concentration was found to be reduced by $12 \%(P<0 \cdot 05)$ and $17 \%(P<0.001)$ after microwaving cabbage for 315 and $420 \mathrm{~s}$ respectively, but unaltered at the different stages of steaming. These findings on the effect of microwaving on glucosinolate concentration do not agree with previous findings (Vallejo et al. 2002; Verkerk \& Dekker, 2004). The study has also shown that plant myrosinase activity is effectively lost after microwaving cabbage for $2 \mathrm{~min}(120 \mathrm{~s}$; loss of $97 \%)$ or steaming for $7 \mathrm{~min}(420 \mathrm{~s}$; loss of $90 \%$; Fig. 2). The reduction in plant myrosinase activity in cabbage at the different stages of cooking was found to be negatively associated with cooking time and the corresponding internal temperature of the cooked cabbage.

In the same study (Rungapamestry et al. 2006) cooked cabbage was incubated in water at $37^{\circ} \mathrm{C}$ for $5 \mathrm{~min}$ to simulate the hydrolysis of sinigrin during the ingestion of cooked cabbage. Sinigrin concentrations in cabbage were found to remain stable during steaming and during the early stages of microwaving. The hydrolysis of sinigrin following cooking yields predominantly 1-cyano-2,3epithiopropane after short periods of cooking and AITC after longer periods. Fig. 3 shows the trend in the formation of 1-cyano-2,3-epithiopropane and AITC on hydrolysis of sinigrin in steamed cabbage. The predominant formation of 1-cyano-2,3-epithiopropane from hydrolysis of sinigrin in raw or near-raw cabbage supports observations from earlier studies involving hydrolysis of raw cabbage (Daxenbichler et al. 1977; Kyung et al. 1995).

In other studies (Matusheski \& Jeffery, 2001; Mithen et al. 2003) the hydrolysis of glucoraphanin in fresh or freeze-dried raw broccoli retaining active myrosinase yields primarily sulforaphane nitrile, instead of the isothiocyanate sulforaphane, as a result of the presence of ESP. When recombinant ESP from broccoli is added to a system of purified glucoraphanin and myrosinase in the presence of $0 \cdot 1 \mathrm{M}-\mathrm{FeSO}_{4}$, the concentration of sulforaphane nitrile produced is proportional to that of ESP (Matusheski et al. 2006). Furthermore, ESP activity is reduced after heating broccoli at $\geq 50^{\circ} \mathrm{C}$ for 5 or $10 \mathrm{~min}$, and on hydrolysis of glucoraphanin in broccoli cooked at $\geq 50^{\circ} \mathrm{C}$ there is an increase in the formation of sulforaphane with a concomitant reduction in the production of sulforaphane nitrile as ESP activity is reduced (Matusheski et al. 2006). Similarly, the reduction in 1-cyano-2,3-epithiopropane formation from samples microwaved or steamed for $\leq 120$ or $420 \mathrm{~s}$ respectively (Rungapamestry et al. 2006) corresponds to an increase in the temperature of cooked cabbage to $>50^{\circ} \mathrm{C}$. It is therefore plausible that cabbage microwaved for $120 \mathrm{~s}$ or steamed for $420 \mathrm{~s}$ produces the high yields of AITC on hydrolysis as a result of the denaturation of ESP at these cooking times and the presence of residual plant myrosinase activity in these samples.

\section{Digestive and post-absorptive fate of glucosinolates after ingestion of brassica vegetables}

An understanding of the digestive and absorptive fate of dietary glucosinolates and their isothiocyanate metabolites has emerged mostly from mechanistic studies in animal models such as rats and hamsters (Brüsewitz et al. 1977; Mennicke et al. 1983; Michaelsen et al. 1994; Duncan et al. 1997; Elfoul et al. 2001). The low recoveries of intact glucosinolates and their metabolites in faeces of animals fed glucosinolates or isothiocyanates suggest that a substantial proportion of ingested glucosinolates and isothiocyanates are metabolised in vivo (Slominski et al. 1988; Bollard et al. 1997; Rouzaud et al. 2003). However, there is little information on the hydrolysis of glucosinolates during and after consumption of brassica vegetables by human subjects. Considering the complexity of the glucosinolate-myrosinase system and the host of factors likely to influence the hydrolysis of glucosinolates in vivo, this information is important in understanding the physiological consequences of brassica consumption. Studies with human subjects have used urinary biomarkers to assess the absorption of isothiocyanates after the intake of glucosinolates from brassica vegetables (Getahun 


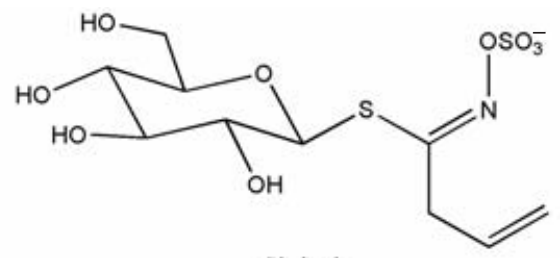

$\mathrm{H}_{2} \mathrm{O}$

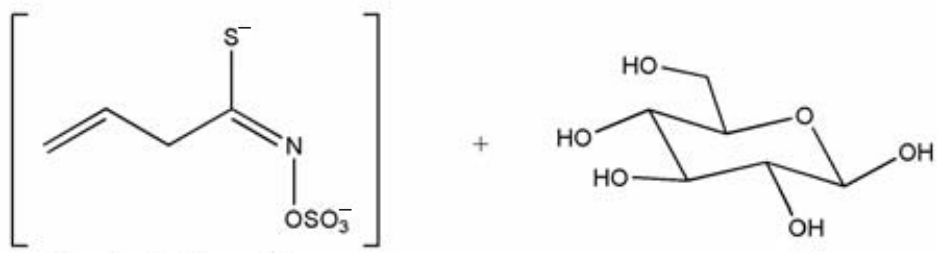

Transient intermediate

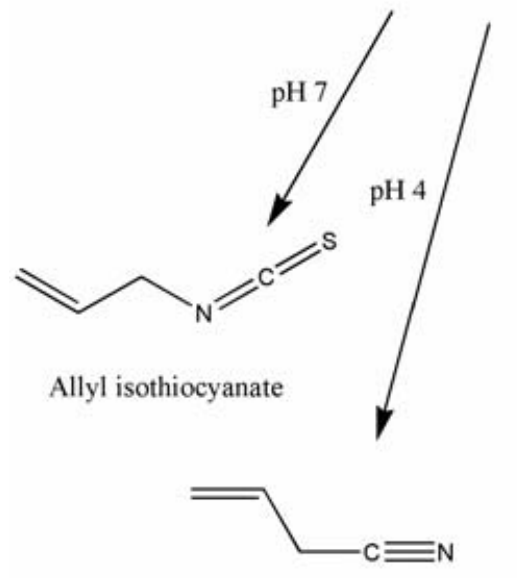

Allyl cyanide

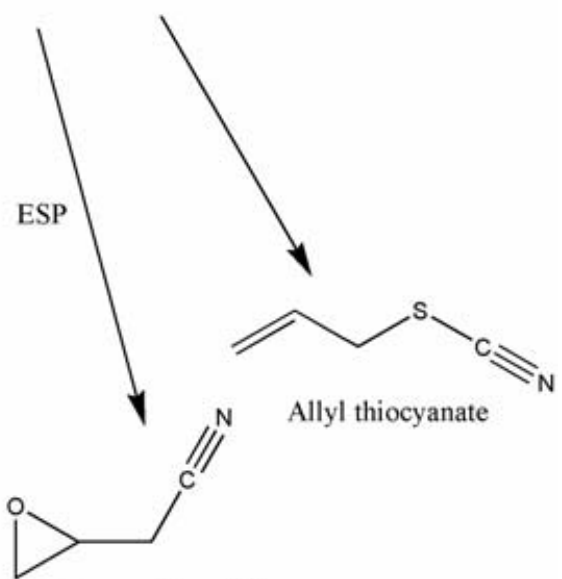

1-Cyano-2,3-epithiopropane

Fig. 1. Hydrolysis of sinigrin into its metabolites under different conditions. ESP, epithiospecifier protein. (From Rouzaud et al. 2004.)

\& Chung, 1999; Conaway et al. 2000; Shapiro et al. 2001; Rouzaud et al. 2004). Following their absorption into the intestinal epithelium isothiocyanates are released into the systemic circulation and metabolized by the mercapturic acid (MA) pathway in the liver. Isothiocyanates initially form conjugates with glutathione, then undergo enzymic modification and are excreted in urine as their corresponding $N$-acetylcysteine conjugates or MA (Brüsewitz et al. 1977; Mennicke et al. 1983). Urinary isothiocyanate MA excretion therefore partially reflects isothiocyanate absorption in vivo, although variation in pre- and postabsorptive recovery may also be important. Thus, so far, only the isothiocyanate MA have been studied as urinary biomarkers of glucosinolate hydrolysis in vivo. This approach has provided a reasonable understanding of the overall uptake of isothiocyanates after consumption of brassica by human subjects (Mennicke et al. 1988; Chung et al. 1998).

\section{Involvement of the colonic microflora in glucosinolate hydrolysis in vivo}

After ingestion of brassica containing active plant myrosinase glucosinolates are quickly hydrolysed in the upper gastrointestinal tract followed by subsequent absorption of isothiocyanates (Rouzaud et al. 2003). Following the intake of brassica devoid of plant myrosinase a large proportion of ingested glucosinolates may reach the colon, where they are subject to hydrolysis by the resident microflora to release isothiocyanates along with other metabolites (Rabot et al. 1993; Krul et al. 2002). 


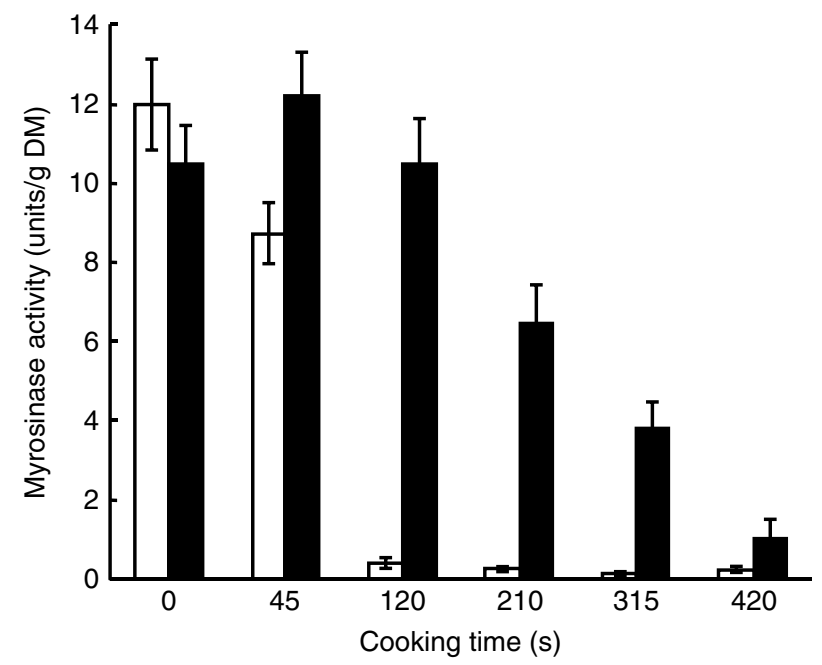

Fig. 2. Plant myrosinase activity, expressed as units/g DM, when $120 \mathrm{~g}$ cabbage (Brassica oleracea var. capitata) was microwaved at $750 \mathrm{~W}(\square)$ or steamed $(\square)$ for six time periods over $7 \mathrm{~min}$. Data are the means with their standard errors represented by vertical bars for six replicates. Myrosinase activity was significantly affected by cooking time $(P<0.001)$ and cooking treatment $(P<0.001)$ and there was a significant interaction between cooking time and treatment $(P<0.001)$.

While the analysis of urinary MA gives some indication of the overall extent of absorption of isothiocyanates after ingestion of glucosinolates and/or isothiocyanates, it does not provide information on the site of hydrolysis within the lumen of the alimentary tract. Although the metabolism and disposition of glucosinolates in different parts of the gastrointestinal tract has not been fully elucidated, the involvement of the colonic microflora in the hydrolysis of glucosinolates both in vitro and in vivo has been documented.

Hydrolysis of glucosinolates has been shown to occur in the colon and caecum of rats fed a meal containing glucosinolates (Michaelsen et al. 1994) and after incubation of glucosinolates with the caecal contents of laying hens (Slominski et al. 1988). Lactobacillus was the first genus of bacteria implicated in the hydrolysis of glucosinolates in vivo in gnotobiotic rats (Nugon-Baudon et al. 1990). When gnotobiotic rats inoculated with a human digestive strain of Bacteroides thetaiotaomicron were dosed with sinigrin (Elfoul et al. 2001), partial hydrolysis of sinigrin to AITC was observed in the large intestine, in which the concentration of $B$. thetaiotaomicron was similar to that in the human colon. Cheng et al. (2004) have shown that sinigrin and glucotropaeolin are hydrolysed in vitro by three species of bifidobacteria of human origin. However, the hydrolysis generates mostly nitriles because of the acidification of the medium by bifidobacteria (Cheng et al. 2004).

The relative contribution of microbial myrosinase to glucosinolate hydrolysis remains to be fully resolved. Plant myrosinase produces a considerable release of isothiocyanates from glucosinolate hydrolysis in vivo when germ-free rats or rats inoculated with human faecal microflora are fed a diet with plant myrosinase (Rouzaud et al. 2003). However, the colonic microflora do not

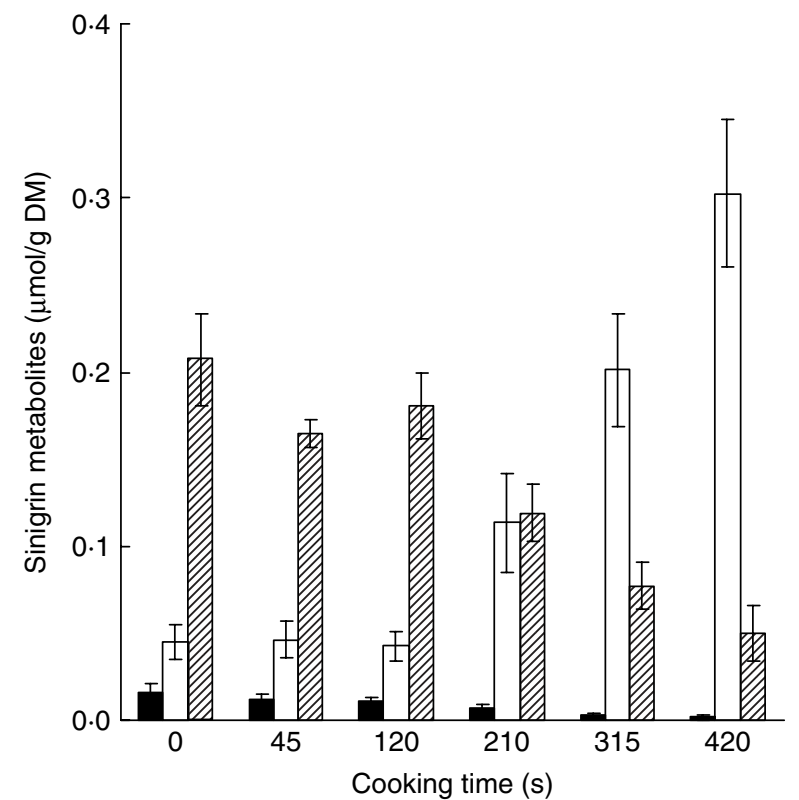

Fig. 3. Concentration of allyl cyanide ( $\square$ ), allyl isothiocyanate ( $\square$ )

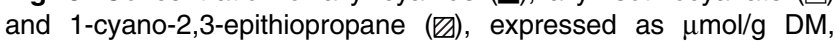
when cooked cabbage (Brassica oleracea var. capitata) was incubated in water at $37^{\circ} \mathrm{C}$ for $5 \mathrm{~min}$ to simulate the hydrolysis of sinigrin during the ingestion of cooked cabbage. Data are means with their standard errors represented by vertical bars for six replicates. Concentrations of derivatives were significantly affected by cooking time $(P<0.001)$.

enhance the effect of plant myrosinase on excretion of MA, as the MA excretion of rats inoculated with human faecal microflora that consume a diet without plant myrosinase is low and comparable with that of germ-free rats. It is possible that after its absorption the recovery of isothiocyanates as their MA may be less efficient after their release in the colon by microbial myrosinase than it would be after release in the upper gastrointestinal tract by plant myrosinase. Furthermore, some of the isothiocyanates released in the colon may be metabolized by colonic microflora before their absorption (Rouzaud et al. 2003). Indeed, it has been shown that incubation of sinigrin and glucotropaeolin with fresh human faeces produces allylamine and benzylamine respectively but no isothiocyanates (Combourieu et al. 2001). It is possible that a high proportion of isothiocyanates released in the colon are converted to amines by the colonic microflora (Combourieu et al. 2001). On incubation of rapeseed (Brassica napus) meal and plant myrosinase with caecal contents of pigs no isothiocyanates could be detected (Maskell \& Smithard, 1994). Krul et al. (2002) have reported for sinigrin that only $19 \%$ is converted to AITC in vitro within a large intestinal model. Thus, glucosinolates may be converted to other classes of metabolites in the colon, of which isothiocyanates constitute a small proportion, or the released isothiocyanates may be further metabolized to unknown compounds by the microflora.

The most direct evidence of colonic hydrolysis of glucosinolates by human subjects comes from a study (Getahun \& Chung, 1999) in which a linear increase in the 
formation of isothiocyanates was observed for $\leq 2 \mathrm{~h}$ after incubating cooked watercress (Nasturtium officinalis) juice, containing glucosinolates but no plant myrosinase, with fresh human faeces anaerobically at $37^{\circ} \mathrm{C}$. Metabolicfate studies with human subjects (Conaway et al. 2000; Shapiro et al. 2001; Rouzaud et al. 2004) have provided indirect evidence of the colonic hydrolysis of glucosinolates after ingestion of cooked brassica, essentially free of active plant myrosinase, compared with raw brassica containing active plant myrosinase. After reducing the colonic microflora of volunteers by mechanical cleansing and oral antibiotics the hydrolysis of glucosinolates and absorption of isothiocyanates following consumption of a meal containing glucosinolates and no plant myrosinase is reduced 9-fold (Shapiro et al. 1998). The delayed absorption and excretion of isothiocyanates after consumption of cooked brassica with limited or no plant myrosinase activity, compared with raw brassica containing active plant myrosinase, provides further indirect evidence for the role of the colonic microflora in the hydrolysis of glucosinolates after consumption of cooked brassica (Conaway et al. 2000; Rouzaud et al. 2004).

\section{Factors influencing the digestive fate of glucosinolates and isothiocyanates in vivo}

The hydrolysis of glucosinolates and absorption of isothiocyanates in vivo may be influenced by a host of factors including: residual glucosinolate concentration and plant myrosinase activity in ingested brassica; whether isothiocyanates are ingested pre-formed or as their glucosinolate precursors; the particle size (e.g. extent of chewing) in brassica containing active plant myrosinase and the composition of the meal within which brassica is consumed. These factors may affect gastrointestinal transit time, the delivery of glucosinolates and/or isothiocyanates to the small intestine for hydrolysis and/or absorption, and the extent of colonic fermentation (Stahl et al. 2002). Furthermore, individuals may vary in their metabolism of glucosinolates as a result of polymorphisms in genes coding for glutathione- $S$-transferases (GST), which catalyse the conjugation of isothiocyanates with glutathione to different extents before excretion of isothiocyanates as MA (Seow et al. 2005).

The residual glucosinolate concentration and plant myrosinase activity within ingested brassica are a function of the effect of preparation and cooking of brassica before their consumption. Recoveries of glucosinolates after their hydrolysis to isothiocyanates and subsequent excretion as MA have been reported to be higher following the intake of raw brassica with active plant myrosinase than following the intake of cooked brassica in which most or all of the plant myrosinase has been denatured. The proportion of glucosinolates absorbed as isothiocyanates and excreted as MA has been reported to be 0.45 and 0.04 after the intake of raw and boiled watercress respectively (Getahun \& Chung, 1999), $0 \cdot 32$ and $0 \cdot 10$ following consumption of raw and steamed broccoli respectively (Conaway et al. 2000), and 0.37 and 0.15 after ingestion of raw and microwaved cabbage respectively (Rouzaud et al. 2004). Despite the consistent observation that plant myrosinase yields a fuller hydrolysis of glucosinolates to isothiocyanates in vivo than the intestinal microflora, there is some uncertainty about the design and calculation of data from some of these experiments. One of the issues relates to the calculation of the intake of glucosinolate precursors, expressed as isothiocyanate equivalents, to determine their recovery after brassica consumption (Getahun \& Chung, 1999; Conaway et al. 2000). The authors have used an exogenous source of plant myrosinase from mustard to hydrolyse glucosinolates within cooked watercress (Getahun \& Chung, 1999) or broccoli (Conaway et al. 2000) in vitro to estimate the concentration of isothiocyanates ingested, but used endogenous plant myrosinase for glucosinolate hydrolysis in the raw brassica counterpart. The source of plant myrosinase has been shown to affect the ratio of metabolites produced on glucosinolate hydrolysis (Petroski \& Tookey, 1982), and this factor may have confounded the intake of isothiocyanate equivalents from raw and cooked brassica in these studies. Furthermore, isothiocyanate intake, determined from the hydrolysis of glucosinolates in vitro, may be misrepresented, since their production in vivo may be confounded by the formation of other metabolites, as well as other factors such as extent of chewing and gastrointestinal transit time. Rouzaud et al. (2004) have expressed MA excretion as a proportion of glucosinolate precursor ingested, measured directly, to calculate glucosinolate recovery and have also quantified plant myrosinase activity within the ingested white cabbage.

Human subjects excrete only a proportion of the ingested dose of glucosinolates or isothiocyanates as MA (Chung et al. 1992; Jiao et al. 1994), and various suggestions have been made to account for the fate of the remaining proportion. The analysis of gut contents of rats fed a diet containing a range of glucosinolates but devoid of plant myrosinase (Michaelsen et al. 1994) has shown that the glucosinolate content in the portion of the gastrointestinal tract from the stomach to the proximal small intestine is 3-20-fold lower than the amount ingested. The authors suggest that the difference is related to the likely degradation of glucosinolates by the low $\mathrm{pH}$ environment of the stomach, in conjunction with metal ions in the feed. It has also been suggested (Elfoul et al. 2001) that sinigrin may be partly absorbed in the upper gastrointestinal tract. When rapeseed meal is incubated with pepsin and $\mathrm{HCl}$ or porcine small intestinal contents at $37^{\circ} \mathrm{C}$ in vitro to simulate transit through the stomach and small intestine, losses in individual glucosinolates vary from 3 to $28 \%$ (Keck et al. 2003). The absence of plant myrosinase in this model may mimic a situation in which cooked brassica devoid of plant myrosinase is consumed. Conversely, the ingestion of brassica containing plant myrosinase may promote hydrolysis of glucosinolates in the stomach and small intestine, where factors such as $\mathrm{pH}$ or meal composition may influence the proportion of the various metabolites that are produced.

The consumption of pre-formed isothiocyanates by human subjects results in a greater absorption of isothiocyanates than is absorbed following consumption of their glucosinolate precursors (Shapiro et al. 1998, 2001; Rouzaud et al. 2004). Absorption and excretion of isothiocyanates is five to seven times higher and occurs at a 
faster rate (with peak excretion occurring approximately $4 \mathrm{~h}$ earlier) after ingestion of pre-formed isothiocyanates than following the intake of an equimolar dose of their glucosinolate precursors in the absence of plant myrosinase (Shapiro et al. 1998, 2001). When volunteers consume preformed AITC in the form of mustard with no plant myrosinase its excretion is 2-fold higher than after its ingestion as its glucosinolate precursor, sinigrin, along with active plant myrosinase in raw cabbage (Rouzaud et al. 2004). The delayed peak in excretion and lower uptake of isothiocyanates following ingestion of glucosinolates, compared with isothiocyanates, suggests that the overall rate and extent of glucosinolate hydrolysis may be dictated by the conversion of glucosinolates to isothiocyanates in vivo (Shapiro et al. 1998).

However, contrasting results have been reported in rodents. When freeze-dried broccoli is hydrolysed in vitro and then fed to rats urinary sulforaphane MA is 5-fold lower than when the broccoli is fed directly in the form of raw freeze-dried broccoli (Keck et al. 2003). The authors suggest that the yield of sulforaphane may be greater after hydrolysis of glucoraphanin by plant myrosinase and intestinal microflora in vivo compared with its hydrolysis by plant myrosinase in vitro before ingestion. A homogenate of fresh cabbage at its natural $\mathrm{pH}$ produces predominantly nitriles instead of isothiocyanates (Daxenbichler et al. 1977; Kyung et al. 1995). Furthermore, hydrolysis of freeze-dried raw broccoli in vitro generates $80 \%$ sulforaphane nitrile and 20\% sulforaphane (Mithen et al. 2003). Consumption of glucosinolates in the form of cooked brassica devoid of plant myrosinase presumably leads to a predominantly localized uptake of isothiocyanates by colonocytes, while ingestion of pre-formed isothiocyanates allows a systemic uptake of isothiocyanates from the proximal intestine in vivo. Evidence from cell lines and animal models suggests that the overall protective effect of isothiocyanates against cancer may be enhanced by their direct uptake by target tissues such as the colonic epithelium (Smith et al. 1998, 2003, 2004).

A further factor influencing the fate of glucosinolates during the ingestion of brassica is the extent of cell rupture during chewing. Only one small-scale study (Shapiro et al. 2001) has explored this aspect, showing that excretion of isothiocyanates in human subjects is 1.5 times higher after raw broccoli sprouts with active plant myrosinase were chewed and swallowed, than when they were swallowed without chewing. Chewing may therefore be an important determinant of the fate of glucosinolates during the consumption of brassica with active plant myrosinase.

The absorption of isothiocyanates has been shown to vary, although not markedly, between individuals. CV of $>10 \%$ have been reported between and within individuals after repeated doses of pre-formed isothiocyanates in human subjects (Shapiro et al. 2001). Low inter-individual variation has been observed after the ingestion of AITC in the form of mustard, with recovery of $60-90 \%$ of the administered doses of AITC (Rouzaud et al. 2004). Interindividual variation is $1 \cdot 5$-fold greater after the ingestion of cooked watercress than after raw watercress (Getahun \& Chung, 1999), indicating that there may be inter-individual differences in the colonic hydrolysis of glucosinolates, in addition to other factors such as gastrointestinal transit time, extent of chewing and genotype. Polymorphisms in genes coding for the activity of GST isoforms have been described (Seow et al. 2005) and they may explain interindividual variation in the metabolism and excretion of isothiocyanates. Individuals with GSTM1- and/or GSTT1null genotypes have been shown to be at reduced risk of developing colo-rectal and lung cancers after the intake of isothiocyanates (Keum et al. 2004). It is possible that the low GST activity and a slower rate of excretion of isothiocyanates in these individuals may help retain more isothiocyanates at target tissues (e.g. colon) and provide a pro-apoptotic effect in situ (Johnson, 2004).

As brassica vegetables are normally consumed as part of a meal, the digestive fate of glucosinolates may be further influenced by the composition of the meal matrix. Isothiocyanates are highly electrophilic and may bind to sulfhydryl, hydroxyl and amino groups produced as a result of the digestion of other meal components (Stahl et al. 2002). Despite a higher yield of isothiocyanates following the ingestion of raw brassica rather than cooked brassica (Getahun \& Chung, 1999; Conaway et al. 2000), the preponderance of nitriles formed after hydrolysis of raw brassica in vitro suggests that consumption of raw brassica containing ESP (Matusheski et al. 2004) may not be the best means of maximizing isothiocyanate uptake in vivo.

In one study (Rungapamestry et al. 2007) the absorption of sulforaphane following consumption of $150 \mathrm{~g}$ lightlycooked (microwaved for $2 \mathrm{~min}$ ) or fully-cooked (microwaved for $5.5 \mathrm{~min}$ ) broccoli, containing glucoraphanin, along with a meat-containing meal or its vegetarian alternative has been investigated in twelve human volunteers. The volunteers received mustard containing $17 \cdot 3$ (SE 0.27) $\mu$ mol pre-formed AITC/g with each meal to control for intra- and inter-individual variation in the absorption and excretion of isothiocyanates. Each meal was separated by a wash-out period of $\geq 48 \mathrm{~h}$. Urine was collected for $24 \mathrm{~h}$ following each meal and analysed for excretion of allyl MA and sulforaphane MA. The expected fate of glucoraphanin and AITC after their ingestion is shown in Fig. 4. Although glucoraphanin intake was not found to be different between broccoli treatments, hydrolysis of glucoraphanin to sulforaphane and absorption of sulforaphane were found to be three times higher after consumption of lightly-cooked broccoli than after fully-cooked broccoli $(P<0 \cdot 001$; Fig. 5). Plant myrosinase activity was found to be four times higher in lightly-cooked broccoli than in fully-cooked broccoli $(P<0 \cdot 001)$, explaining the higher total output of sulforaphane MA after consumption of lightly-cooked broccoli. The meal matrix was found to influence the excretion of pre-formed AITC from mustard as allyl MA, but not the hydrolysis of glucoraphanin and its excretion as sulforaphane MA from cooked broccoli. Absorption of AITC from mustard was found to be about 1.3-fold higher following consumption of the meatcontaining meal than following the vegetarian meal $(P<0 \cdot 001$; Fig. 6). However, the fat content of the meatcontaining meal was shown to be five times higher than that of the vegetarian meal and may have facilitated the absorption of pre-formed isothiocyanates, which are relatively hydrophobic. 
<smiles></smiles>

Glucoraphanin from lightly- or fully-cooked broccoli<smiles>CCCS(=O)CCCCN(NC(=S)SCC(NC(C)=O)C(=O)O)C(=O)O</smiles><smiles>C=CCN=C=S</smiles>

AITC from mustard<smiles>C=CCN=C=S</smiles><smiles>C=CCNC(=S)SCC(NC(C)=O)C(=O)O</smiles>

Allyl mercapturic acid

Fig. 4. Expected metabolic fate of glucoraphanin and allyl isothiocyanate (AITC) following ingestion of cooked broccoli (Brassica oleracea var. italica) and mustard (Sinapis alba) respectively by human volunteers. (Adapted from Rungapamestry et al. 2007.)

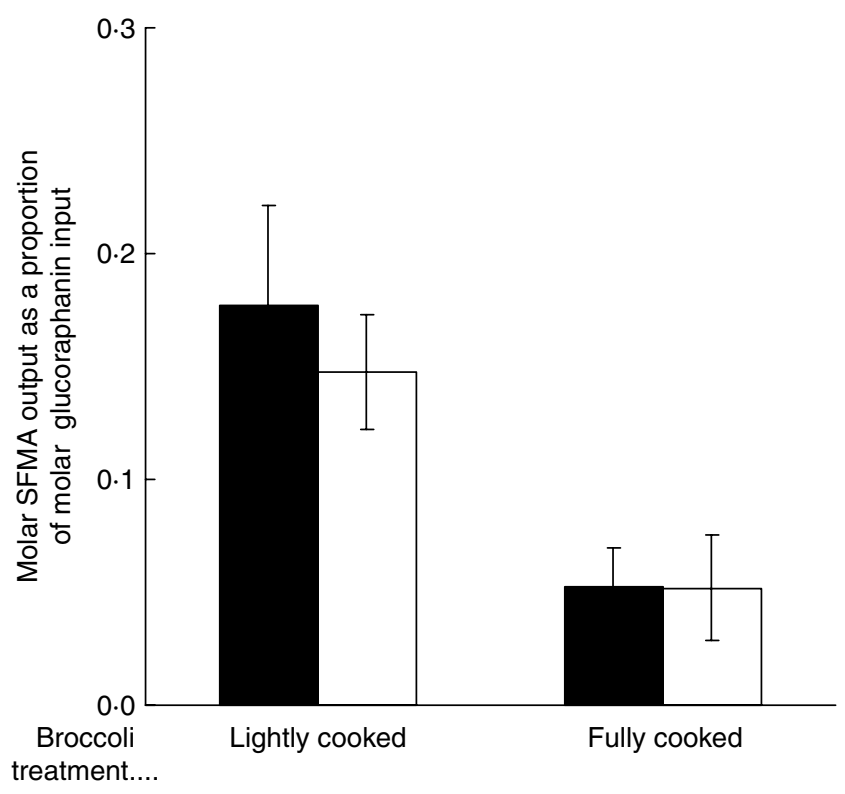

Fig. 5. Total excretion of sulforaphane mercapturic acid (SFMA; $\mu \mathrm{mol})$ over $24 \mathrm{~h}$, as a proportion of glucoraphanin intake ( $\mu \mathrm{mol})$, after consumption of lightly-cooked or fully-cooked broccoli (Brassica oleracea var. italica) along with a meat-containing ( $\square$ ) or vegetarian ( $\square$ ) meal. Data are means with their standard errors represented by vertical bars for twelve replicates. SFMA output was significantly influenced by broccoli treatment $(P<0 \cdot 001)$.

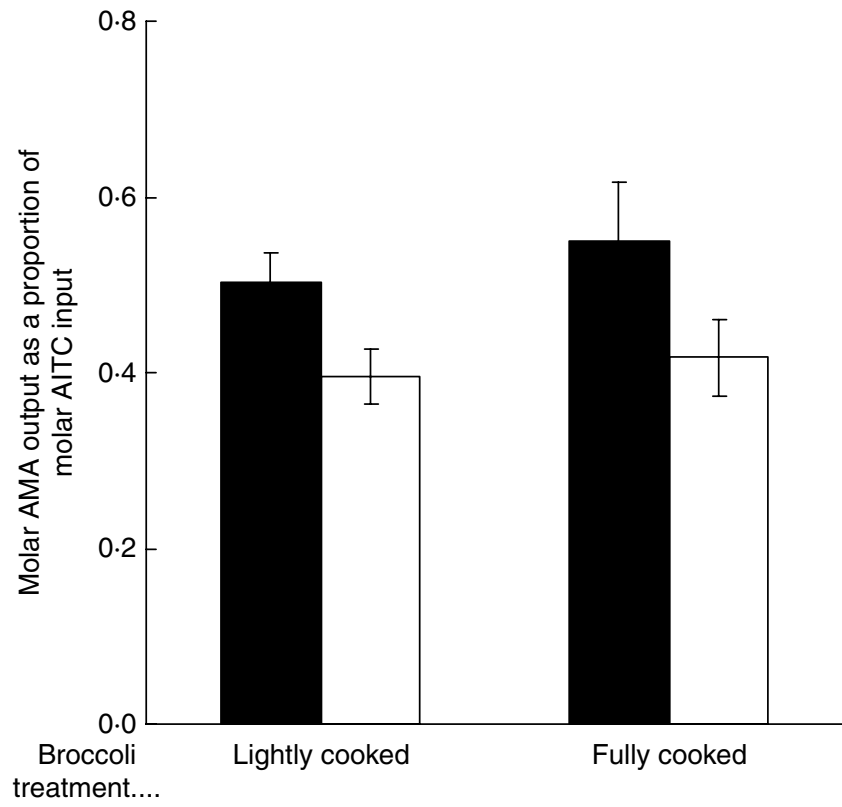

Fig. 6. Total excretion of allyl mercapturic acid (AMA; $\mu \mathrm{mol}$ ) over $24 \mathrm{~h}$, as a proportion of allyl isothiocyanate (AITC) intake ( $\mu \mathrm{mol})$, after consumption of mustard (Sinapis alba) along with a meatcontaining $(\square)$ or vegetarian $(\square)$ meal. Data are means with their standard errors represented by vertical bars for twelve replicates. AMA output was significantly affected by meal composition $(P<0 \cdot 001)$. 
Inter-individual variations of $\leq 4$-fold in total sulforaphane MA output, similar to the variation reported by Getahun \& Chung (1999) after consuming cooked watercress, has been observed (Rungapamestry et al. 2007) after the intake of cooked broccoli. The main influence on the absorption of isothiocyanates in vivo is the way in which brassica is cooked, rather than the effect of the meal matrix. However, isothiocyanates may interact with the meal matrix to a greater extent if they are ingested preformed rather than after their production from the hydrolysis of glucosinolates in vivo.

\section{Conclusion}

The glucosinolate-myrosinase system shows remarkable variation during the processing and ingestion of brassica vegetables. Glucosinolate concentrations are affected by storage temperature and time, while cutting may produce variable effects. Cooking brassica by a range of methods can affect glucosinolate concentrations, plant myrosinase activity and concentrations of its cofactors, and alter the digestive fate of glucosinolates after consumption. Since most vegetables in the UK are processed to some extent before consumption, further research on cooking-induced changes in the glucosinolate content of brassica are required to optimize their intake as part of health-promoting strategies. In addition to residual glucosinolate concentrations and plant myrosinase activity within cooked brassica, the digestive fate of glucosinolates and uptake of isothiocyanates may be influenced by the extent of chewing, gastrointestinal transit time, meal composition, individual genotype and differences in colonic hydrolysis of glucosinolates. An appreciation of these sources of variation may help to better understand the health benefits conveyed through the ingestion of processed brassica vegetables. The present review has highlighted the complex nature of the glucosinolate-myrosinase system, and this complexity makes the formulation of recommendations difficult. More mechanistic studies, investigating the effect of cooking on the metabolic fate of glucosinolates and the release of various metabolites of glucosinolates after ingestion of brassica, may help to complement epidemiological research on brassica consumption and cancer prevention.

\section{Acknowledgements}

The findings reported by the authors were generated from experiments supported financially by the Food Standards Agency (contract no. T01027; Influence of cooking and processing of brassica vegetables on the release of beneficial and harmful metabolites of glucosinolates in the digestive tract). The authors wish to acknowledge the volunteers for taking part in the human feeding trial and $\mathrm{Dr}$ Mark Brewer (Biomathematics and Statistics Scotland) for statistical advice.

\section{References}

Begum S \& Brewer MS (2001) Physical, chemical and sensory quality of microwave-blanched snow peas. Journal of Food Quality 24, 479-493.
Benner M, Geerts RFR, Linnemann AR, Jongen WMF, Folstar P \& Cnossen HJ (2003) A chain information model for structured knowledge management: towards effective and efficient food product improvement. Trends in Food Science \& Technology 14, 469-477.

Bollard M, Stribbling S, Mitchell S \& Caldwell J (1997) The disposition of allyl isothiocyanate in the rat and mouse. Food and Chemical Toxicology 35, 933-943.

Bones AM \& Rossiter JT (1996) The myrosinase-glucosinolate system, its organisation and biochemistry. Physiologia Plantarum 97, 194-208.

Brewer MS, Begum S \& Bozeman A (1995) Microwave and conventional blanching effects on chemical, sensory, and color characteristics of frozen broccoli. Journal of Food Quality 18, 479-493.

Brown AF, Yousef GG, Jeffrey EH, Klein BP, Wallig MA, Kushad MM \& Juvik JA (2002) Glucosinolate profiles in broccoli: Variation in levels and implications in breeding for cancer chemoprotection. Journal of the American Society for Horticultural Science 127, 807-813.

Brüsewitz G, Cameron BD, Chasseaud LF, Görler K, Hawkins DR, Koch H \& Mennicke WH (1977) The metabolism of benzyl isothiocyanate and its cysteine conjugate. Biochemical Journal 162, 99-107.

Cheng DL, Hashimoto K \& Uda Y (2004) In vitro digestion of sinigrin and glucotropaeolin by single strains of Bifidobacterium and identification of the digestive products. Food and Chemical Toxicology 42, 351-357.

Chung FL, Jiao D, Getahun SM \& Yu MC (1998) A urinary biomarker for uptake of dietary isothiocyanates in humans. Cancer Epidemiology, Biomarkers and Prevention 7, 103-108.

Chung FL, Morse MA, Eklind KI \& Lewis J (1992) Quantitation of human uptake of the anticarcinogen phenethyl isothiocyanate after a watercress meal. Cancer Epidemiology, Biomarkers and Prevention 1, 383-388.

Ciska E \& Kozlowska H (2001) The effect of cooking on the glucosinolates content in white cabbage. European Food Research and Technology 212, 582-587.

Combourieu B, Elfoul L, Delort AM \& Rabot S (2001) Identification of new derivatives of sinigrin and glucotropaeolin produced by the human digestive microflora using $\mathrm{H}-1 \mathrm{nmR}$ spectroscopy analysis of in vitro incubations. Drug Metabolism and Disposition 29, 1440-1445.

Conaway CC, Getahun SM, Liebes LL, Pusateri DJ, Topham DKW, Botero-Omary M \& Chung FL (2000) Disposition of glucosinolates and sulforaphane in humans after ingestion of steamed and fresh broccoli. Nutrition and Cancer 38, 168-178.

Daxenbichler ME, Vanetten CH \& Spencer GF (1977) Glucosinolates and derived products in cruciferous vegetables. Identification of organic nitriles from cabbage. Journal of Agricultural and Food Chemistry 25, 121-124.

Dekker M \& Verkerk R (2003) Dealing with variability in food production chains: a tool to enhance the sensitivity of epidemiological studies on phytochemicals. European Journal of Nutrition 42, 67-72.

Dekker M, Verkerk R \& Jongen WMF (2000) Predictive modelling of health aspects in the food production chain: a case study on glucosinolates in cabbage. Trends in Food Science \& Technology 11, 174-181.

Devos RH \& Blijleven WGH (1988) The effect of processing conditions on glucosinolates in cruciferous vegetables. Zeitschrift für Lebensmittel-Untersuchung und -Forschung 187, 525-529.

Duncan AJ, Rabot S \& Nugon-Baudon L (1997) Urinary mercapturic acids as markers for the determination of isothiocyanate release from glucosinolates in rats fed a cauliflower 
diet. Journal of the Science of Food and Agriculture 73, 214-220.

Elfoul L, Rabot S, Khelifa N, Quinsac A, Duguay A \& Rimbault A (2001) Formation of allyl isothiocyanate from sinigrin in the digestive tract of rats monoassociated with a human colonic strain of Bacteroides thetaiotaomicron. FEMS Microbiology Letters 197, 99-103.

Fahey JW, Zalcmann AT \& Talalay P (2001) The chemical diversity and distribution of glucosinolates and isothiocyanates among plants. Phytochemistry 56, 5-51.

Farnham MW, Wilson PE, Stephenson KK \& Fahey JW (2004) Genetic and environmental effects on glucosinolate content and chemoprotective potency of broccoli. Plant Breeding 123, 60-65.

Fenwick GR \& Heaney RK (1983) Glucosinolates and their breakdown products in cruciferous crops, foods and feedingstuffs. Food Chemistry 11, 249-271.

Fenwick GR, Heaney RK \& Mullin WJ (1983) Glucosinolates and their breakdown products in food and food plants. Critical Reviews in Food Science and Nutrition 18, 123-201.

Getahun SM \& Chung FL (1999) Conversion of glucosinolates to isothiocyanates in humans after ingestion of cooked watercress. Cancer Epidemiology, Biomarkers and Prevention 8 , 447-451.

Goodrich RM, Anderson JL \& Stoewsand GS (1989) Glucosinolate changes in blanched broccoli and Brussels-sprouts. Journal of Food Processing and Preservation 13, 275-280.

International Agency for Research on Cancer (2004) IARC Handbooks of Cancer Prevention: Cruciferous Vegetables, Isothiocyanates and Indoles. Lyon: IARC Press.

Jiao D, Ho CT, Foiles P \& Chung FL (1994) Identification and quantification of the $\mathrm{N}$-acetylcysteine conjugate of allyl isothiocyanate in human urine after ingestion of mustard. Cancer Epidemiology, Biomarkers and Prevention 3, 487-492.

Johnson IT (2004) New approaches to the role of diet in the prevention of cancers of the alimentary tract. Mutation Research 551, 9-28.

Kassahun BW, Velisek J \& Davidek J (1995) Glucosinolates in cooked cabbage (Brassica oleracea L. var. Capitata). Potravinarske Vedy 13, 93-102.

Keck AS, Qiao QY \& Jeffery EH (2003) Food matrix effects on bioactivity of broccoli-derived sulforaphane in liver and colon of F344 rats. Journal of Agricultural and Food Chemistry 51, 3320-3327.

Keum YS, Jeong WS \& Tony Kong AN (2004) Chemoprevention by isothiocyanates and their underlying molecular signaling mechanisms. Mutation Research 555, 191-202.

Krul C, Humblot C, Philippe C, Vermeulen M, van Nuenen M, Havenaar R \& Rabot S (2002) Metabolism of sinigrin (2-propenyl glucosinolate) by the human colonic microflora in a dynamic in vitro large-intestinal model. Carcinogenesis 23, 1009-1016.

Kushad MM, Brown AF, Kurilich AC, Juvik JA, Klein BP, Wallig MA \& Jeffery EH (1999) Variation of glucosinolates in vegetable crops of Brassica oleracea. Journal of Agricultural and Food Chemistry 47, 1541-1548.

Kyung KH, Fleming HP, Young CT \& Haney CA (1995) 1-Cyano-2,3-epithiopropane as the primary sinigrin hydrolysis product of fresh cabbage. Journal of Food Science 60, $157-159$.

Lambrix V, Reichelt M, Mitchell-Olds T, Kliebenstein DJ \& Gershenzon J (2001) The Arabidopsis epithiospecifier protein promotes the hydrolysis of glucosinolates to nitriles and influences Trichoplusia in herbivory. Plant Cell 13, 2793-2807.

Ludikhuyze L, Ooms V, Weemaes C \& Hendrickx M (1999) Kinetic study of the irreversible thermal and pressure inactivation of myrosinase from broccoli (Brassica oleracea L. cv. Italica). Journal of Agricultural and Food Chemistry 47, 1794-1800.

Ludikhuyze L, Rodrigo L \& Hendrickx M (2000) The activity of myrosinase from broccoli (Brassica oleracea L. cv. Italica): Influence of intrinsic and extrinsic factors. Journal of Food Protection 63, 400-403.

Maskell I \& Smithard R (1994) Degradation of glucosinolates during in-vitro incubations of rapeseed meal with myrosinase (EC 3.2.3.1) and with pepsin (EC 3.4.23.1) hydrochloric acid, and contents of porcine small intestine and cecum. British Journal of Nutrition 72, 455-466.

Matusheski NV \& Jeffery EH (2001) Comparison of the bioactivity of two glucoraphanin hydrolysis products found in broccoli, sulforaphane and sulforaphane nitrile. Journal of Agricultural and Food Chemistry 49, 5743-5749.

Matusheski NV, Juvik JA \& Jeffery EH (2004) Heating decreases epithiospecifier protein activity and increases sulforaphane formation in broccoli. Phytochemistry 65, 1273-1281.

Matusheski NV, Swarup R, Juvik JA, Mithen R, Bennett M \& Jeffery EH (2006) Epithiospecifier protein from broccoli (Brassica oleracea L. ssp. italica) inhibits formation of the anticancer agent sulforaphane. Journal of Agricultural and Food Chemistry 54, 2069-2076.

Mennicke WH, Gorler K \& Krumbiegel G (1983) Metabolism of some naturally-occurring isothiocyanates in the rat. Xenobiotica 13, 203-207.

Mennicke WH, Gorler K, Krumbiegel G, Lorenz D \& Rittmann $\mathrm{N}$ (1988) Studies on the metabolism and excretion of benzyl isothiocyanate in man. Xenobiotica 18, 441-447.

Michaelsen S, Otte J, Simonsen LO \& Sorensen H (1994) Absorption and degradation of individual intact glucosinolates in the digestive-tract of rodents. Acta Agriculturae Scandinavica 44, 25-37.

Mithen R, Faulkner K, Magrath R, Rose P, Williamson G \& Marquez J (2003) Development of isothiocyanate-enriched broccoli, and its enhanced ability to induce phase 2 detoxification enzymes in mammalian cells. Theoretical and Applied Genetics 106, 727-734.

Mithen RF (2001) Glucosinolates and their degradation products. Advances in Botanical Research 35, 213-262.

Nugon-Baudon L, Rabot S, Wal JM \& Szylit O (1990) Interactions of the intestinal microflora with glucosinolates in rapeseed meal toxicity - 1st evidence of an intestinal lactobacillus possessing a myrosinase-like activity in vivo. Journal of the Science of Food and Agriculture 52, 547-559.

Oerlemans K, Barrett DM, Suades CB, Verkerk R \& Dekker M (2006) Thermal degradation of glucosinolates in red cabbage. Food Chemistry 95, 19-29.

Petroski RJ \& Tookey HL (1982) Interactions of thioglucoside glucohydrolase and epithiospecifier protein of cruciferous plants to form 1-cyanoepithioalkanes. Phytochemistry 21, 1903-1905.

Pihakaski K \& Pihakaski S (1978) Myrosinase in Brassicaceae (Cruciferae) II. Myrosinase activity in different organs of Sinapis alba L. Journal of Experimental Botany 29, 335-345.

Pocock K, Heaney RK, Wilkinson AP, Beaumont JE, Vaughan JG \& Fenwick GR (1987) Changes in myrosinase activity and isoenzyme pattern, glucosinolate content and the cytology of myrosin cells in the leaves of heads of 3 cultivars of English white cabbage. Journal of the Science of Food and Agriculture 41, 245-257.

Rabot S, Nugon-Baudon L, Raibaud P \& Szylit O (1993) Rapeseed meal toxicity in gnotobiotic rats: influence of a whole human fecal flora or single human strains of Escherichia coli and Bacteroides vulgatus. British Journal of Nutrition 70, 323-331. 
Rangkadilok N, Tomkins B, Nicolas ME, Premier RR, Bennett RN, Eagling DR \& Taylor PWJ (2002) The effect of postharvest and packaging treatments on glucoraphanin concentration in broccoli (Brassica oleracea var. italica). Journal of Agricultural and Food Chemistry 50, 7386-7391.

Rodrigues AS \& Rosa EAS (1999) Effect of post-harvest treatments on the level of glucosinolates in broccoli. Journal of the Science of Food and Agriculture 79, 1028-1032.

Rosa EAS \& Heaney RK (1993) The effect of cooking and processing on the glucosinolate content - Studies on 4 varieties of Portuguese cabbage and hybrid white cabbage. Journal of the Science of Food and Agriculture 62, 259-265.

Rouzaud G, Rabot S, Ratcliffe B \& Duncan AJ (2003) Influence of plant and bacterial myrosinase activity on the metabolic fate of glucosinolates in gnotobiotic rats. British Journal of Nutrition 90, 395-404.

Rouzaud G, Young SA \& Duncan AJ (2004) Hydrolysis of glucosinolates to isothiocyanates after ingestion of raw or microwaved cabbage by human volunteers. Cancer Epidemiology, Biomarkers and Prevention 13, 125-131.

Rungapamestry V, Duncan AJ, Fuller Z \& Ratcliffe B (2006) Changes in glucosinolate concentrations, myrosinase activity and production of metabolites of glucosinolates in cabbage (Brassica oleracea var. capitata) cooked for different durations. Journal of Agricultural and Food Chemistry 54, $7628-7634$

Rungapamestry V, Duncan AJ, Fuller Z \& Ratcliffe B (2007) Effect of meal composition and cooking duration on the fate of sulforaphane following consumption of broccoli by healthy human subjects. British Journal of Nutrition (In the Press).

Seow A, Vainio H \& Yu MC (2005) Effect of glutathione-Stransferase polymorphisms on the cancer preventive potential of isothiocyanates: An epidemiological perspective. Mutation Research 592, 58-67.

Shapiro TA, Fahey JW, Wade KL, Stephenson KK \& Talalay P (1998) Human metabolism and excretion of cancer chemoprotective glucosinolates and isothiocyanates of cruciferous vegetables. Cancer Epidemiology, Biomarkers and Prevention 7, 1091-1100.

Shapiro TA, Fahey JW, Wade KL, Stephenson KK \& Talalay P (2001) Chemoprotective glucosinolates and isothiocyanates of broccoli sprouts: Metabolism and excretion in humans. Cancer Epidemiology, Biomarkers and Prevention 10, 501-508.

Shikita M, Fahey JW, Golden TR, Holtzclaw WD \& Talalay P (1999) An unusual case of 'uncompetitive activation' by ascorbic acid: purification and kinetic properties of a myrosinase from Raphanus sativus seedlings. Biochemical Journal 341, 725-732.

Slominski BA, Campbell LD \& Stanger NE (1988) Extent of hydrolysis in the intestinal-tract and potential absorption of intact glucosinolates in laying hens. Journal of the Science of Food and Agriculture 42, 305-314.

Smith TK, Lund EK \& Johnson IT (1998) Inhibition of dimethylhydrazine-induced aberrant crypt foci and induction of apoptosis in rat colon following oral administration of the glucosinolate sinigrin. Carcinogenesis 19, 267-273.

Smith TK, Lund EK, Parker ML, Clarke RG \& Johnson IT (2004) Allyl-isothiocyanate causes mitotic block, loss of cell adhesion and disrupted cytoskeletal structure in HT29 cells. Carcinogenesis 25, 1409-1415.

Smith TK, Mithen R \& Johnson IT (2003) Effects of Brassica vegetable juice on the induction of apoptosis and aberrant crypt foci in rat colonic mucosal crypts in vivo. Carcinogenesis $\mathbf{2 4}$, 491-495.

Sones K, Heaney RK \& Fenwick GR (1984) An estimate of the mean daily intake of glucosinolates from cruciferous vegetables in the UK. Journal of the Science of Food and Agriculture 35, 712-720.

Springett MB \& Adams JB (1989) Properties of Brussels-sprouts thioglucosidase. Food Chemistry 33, 173-186.

Stahl W, van den Berg H, Arthur J, Bast A, Dainty J, Faulks RM, Gartner C, Haenen G, Hollman P \& Holst B (2002) Bioavailability and metabolism. Molecular Aspects of Medicine 23, 39-100.

Tookey HL (1973) Crambe thioglucoside glucohydrolase (EC 3.2.3.1): Separation of a protein required for epithiobutane formation. Canadian Journal of Biochemistry 51, 1654-1660.

Vallejo F, Tomas-Barberan F \& Garcia-Viguera C (2003) Health-promoting compounds in broccoli as influenced by refrigerated transport and retail sale period. Journal of Agricultural and Food Chemistry 51, 3029-3034.

Vallejo F, Tomas-Barberan FA \& Garcia-Viguera C (2002) Glucosinolates and vitamin $\mathrm{C}$ content in edible parts of broccoli florets after domestic cooking. European Food Research and Technology 215, 310-316.

van Poppel G, Verhoeven DTH, Verhagen H \& Goldbohm RA (1999) Brassica vegetables and cancer prevention - Epidemiology and mechanisms. Advances in Experimental Medicine and Biology 472, 159-168.

Verkerk R \& Dekker M (2004) Glucosinolates and myrosinase activity in red cabbage (Brassica oleracea L. var. Capitata $\mathrm{f}$. rubra DC.) after various microwave treatments. Journal of Agricultural and Food Chemistry 52, 7318-7323.

Verkerk R, Dekker M \& Jongen WMF (2001) Post-harvest increase of indolyl glucosinolates in response to chopping and storage of Brassica vegetables. Journal of the Science of Food and Agriculture 81, 953-958.

Wathelet JP, Mabon N, Foucart M \& Marlier M (1996) Influence of blanching on the quality of Brussels sprouts (Brassica oleracea L. cv. gemmifera). Sciences des Aliments 16, 393-402.

Wilkinson AP, Rhodes MJC \& Fenwick RG (1984) Myrosinase activity of cruciferous vegetables. Journal of the Science of Food and Agriculture 35, 543-552.

Yadav SK \& Sehgal S (1995) Effect of home processing on ascorbic-acid and beta-carotene content of spinach (Spinacia oleracia) and amaranth (Amaranthus tricolor) leaves. Plant Foods for Human Nutrition 47, 125-131.

Yen GC \& Wei QK (1993) Myrosinase activity and total glucosinolate content of cruciferous vegetables, and some properties of cabbage myrosinase in Taiwan. Journal of the Science of Food and Agriculture 61, 471-475.

Zhang YS, Yao S \& Li J (2006) Vegetable-derived isothiocyanates: anti-proliferative activity and mechanism of action. Proceedings of the Nutrition Society 65, 68-75. 